\title{
Augmentation of Demineralized Bone Matrix Post-Tooth Extraction Increases The Density of Gingival Collagen Fiber of Rabbit Mandible
}

\author{
Regina TC. Tandelilin \\ Department of Oral Biology, Faculty of Dentistry, \\ Universitas Gadjah Mada, \\ Yogyakarta, Indonesia \\ E-mail: regina30mei@yahoo.com \\ Received August 15, 2010; Accepted September 15, 2010
}

\begin{abstract}
Most cases report that the abnormality of bone defect is engendered by tooth extraction. The powder of demineralized bone matrix (DBM) is required to fill alveolus bone for reconstructing material or preventing tissues defect after tooth extraction. The aim of this study was to determine the density of gingival collagen fiber on wound healing after the augmentation of DBM following the extraction of incisivus tooth. In this study, 36 male rabbits aged 2.5-3 months weighing 900-1,100 grams were randomly divided into two groups: control and treated rabbits. The incisivus teeth of mandibles of treated rabbits were extracted and augmented with the allograft DBM powder. The gingival was sutured with non-absorbable sutures. The same procedures were employed to the control group, except that these rabbits were augmented with DBM powder. Subsequently, the rabbits were sacrificed on days 1, 3, 5, 7, 10, and 14 after surgery, and each observation was represented by three rabbits in the sample. The gingival $(\mathrm{ca} .0 .5-1 \mathrm{~cm})$ was cut and fixed immediately in $10 \%$ paraformaldehide. The staining was done using van Geison. In the treated rabbits, the density of gingival collagen fiber significantly increases in all observation days except on first day, indicating that the allograft powder of DBM successfully accelerates the wound healing process.
\end{abstract}

Keywords: Demineralized bone matrix, collagen fiber, transplantation, augmentation.

\section{Introduction}

Transplantation purports to reconstruct parts of body that are defect due to traumas or diseases. Trauma happening in mouth hollow is primarily rendered by the effect of tooth extraction. This may cause damage to alveolus bone; for instance, a finding reported by Mercier ${ }^{1}$ shows that bone abnormality in the realm of dental surgery is mainly damage to bone after tooth extraction. Treatment or prevention of bone damage can be undertaken by giving bone graft for augmentation to induce the growth of new bone. ${ }^{2,3}$
Marx et al. ${ }^{4}$ report that the graft contains conductive matrixes, inductive cells, and factors that physiologically play a role in the healing process. Success in graft augmentation requires several prerequisites ${ }^{2,3,5}$ eliminating immunogenic components that basically contain protein, being free from infection, being absent from bone marrow, and not having systemic diseases.

Demineralized bone matrix (DBM) is a dry and coagulated allograft that can be stored in room temperature. Its biochemical character is slightly decreasing since the drainage utilizes a coagulated approach and the sterilization harnesses Gamma $(\gamma)$ ray. This graft has an advantage of alleviating the 
prevalence of immune reaction and of being user friendly. Previous intensive research has provided evidence of DBM's ability to induce the formation of bone ${ }^{6,7}$. Tandelilin et al. ${ }^{8}$ find that DBM induces the density of the growth of bone collagen fiber. DBM also enhances the density of osteoblast ${ }^{9}$. DBM powder is composed of collagen and non-collagen contents. According to Wozney ${ }^{10}$, DBM allograft contains bone morphogenic protein (BMP), platelet derived growth factor (PDGF), and transforming growth factor (TGF- $\beta$ ).

Brunsvold and Mellonig ${ }^{11}$ indicate that DBM is beneficial in the rehabilitation process following jaw resection, jaw fracture, jaw cyst extirpation, preprosthetic surgery, augmentation around tooth implant, and augmentation of bone damage due to abnormality in periodontal tissue, augmentation of alveolar processus resorption on a toothless jaw, augmentation post-extraction of many teeth, and augmentation of alveolus post-odontectomi. For a simple case aimed at filling a cavity, only cancellous cubical, cancellous chip, or powder are needed.

Wound healing is basically a process or effort to overhaul damages to both hard tissues and soft tissues. In other words, this healing process is a response to the prevalence of laceration, physically and chemically, to tissues in the mechanism of structural maintenance such that the tissues' functions return to be normal ${ }^{12}$. Peterson et al. ${ }^{13}$ reveal that physical laceration to soft tissues can take forms of little or massive surgical incision, pressure, extreme changes in temperature, irradiation, and blockage in artery and vena flows. Physical laceration to hard and soft tissues can occur simultaneously; for instance, in the case of wound post-tooth extraction.

Wound healing embraces a series of processes, such as chemotaxis, cell division, neovascularization, synthesis of new ECM components, formation and reformation of scraped tissues. Dissolved mediators such as growth factor, cytokine, matrix metalloproteinase (MMP) and its regulator are able to control stages involved in wound healing through their effects on several cells and extra-cell membrane henceforth called ECM ${ }^{14}$.
Acute wounds triggered by tissue laceration involve several phases. The physiology of natural acute wound healing occurs in three phases: inflammation, proliferation, and remodeling or maturation. Those three phases will proceed normally so long as no disturbances prevail, both internally and externally. The main component in the healing process of soft tissues is collagen alongside epithelial cells. Fibroblast is a cell responsible for collagen synthesis. Final result of synthesis and degradation yields the remodeling of skeleton of bundle tissues-an important step in chronic inflammation and wound healing ${ }^{15}$.

As widely known, collagen is a protein most found in the body and composed of glycine amino acid of $33.5 \%$, proline of $12 \%$, proline hydroxyl of $10 \%$, and other amino acids. In human body, collagen is the most found protein, constituting $30 \%$ to the total protein ${ }^{16}$. Prockop and Kivirikko ${ }^{17}$ find evidence that the types of collagen have reached more than 20 categories spread throughout human body. However, the most found and learned are types I, II, III, IV, and V. Type I collagen is the most found and widely spread. It prevails as the structure in tissues, hence is labeled as collagen fiber. In addition, it is also extant in the formation of bone, dentin, tendon, dermis, and gingival ${ }^{16,18}$. Alongside type I collagen is also found type III collagen in gingival.$^{18}$

Collagen fiber consists of extremely delicate fibers. According to Fawcet ${ }^{19}$ this fiber looks white when bundled with sheaves. Collagen fiber comprises collagen protein with its molecules composed of three $\alpha$ polypeptide chains and stacked in the form of triple helix ${ }^{20}$. Collagen is produced in endoplasmic reticulum of fibroblast cell in the form of procollagen, intermediated by vesicle and secreted from cell surface. Subsequently, procollagen will be polymerized to be tropocollagen that has a length of $280 \mathrm{~nm}^{16}$. These molecules are then cross-linkingly stacked so as to form collagen fiber ${ }^{21}$. Collagen fiber is strong and resistant to tension but flexible enough and collagen bundle often looks wavy ${ }^{22}$. Net accumulation of collagen hinges on both synthesis and collagen degradation. Excessive formation of collagen will also be harmful as it may press and damage its original tissues or can form colloid ${ }^{23}$. This 
study purports to observe the effect of demineralized bone matrix fiber augmentation in wound healing post-tooth extraction on the density of gingival collagen in rabbits' mandibles.

\section{Materials and Methods}

This study utilizes 36 male rabbits weighed $900-1,100$ grams and aged 2.5-3 months. This sample was randomly divided into two groups: control and treatment groups. Control group then underwent extractions of bottom incisivus teeth, which was then augmented by DBM powder (370-710 $\mu \mathrm{M})$. The making and augmentation of DBM, analgesic treatment, and caring mechanisms followed the approaches of Tandelilin et al. ${ }^{8}$ and Tandelilin ${ }^{9}$. Subsequently, non-absorbable thread No. 0-5 was used to close the gingival. The same treatment was given to the control group without DBM augmentation.

Next, the rabbits were killed, with previously being put to sleep, on days $1,3,5,7,10$, and 14 postsurgery, and each group was represented by three rabbits. Gingivals with an approximate width of 0.5 $1 \mathrm{~cm}^{2}$ in the extraction area for all specimens were taken and fixated in paraformaldehyde solution $10 \%$. This process continued with the making of Van Geison glassslide inventory to see the density of collagen fiber.

Light microscope with 400x magnification was used to observe the density of collagen fiber in gingival. This observation was based on grading determination: grade 1 for thin collagen density, grade 2 for medium density, and grade 3 for thick density (Figure 1). Subsequently, this was examined and analyzed using Man-Whitney test between treatment groups based on observation days.

\section{Results}

Means and standard deviations of the density of gingival collagen fiber for treatment and control groups based on observation days are summarized in Table 1. Next, Figure 2 shows the increasing pattern of the density of collagen fiber growth based on results in Table 1. The formation of collagen fiber has been seen histologically since day 3 , but this is less obvious for control group in which fiber spiral has yet to appear and fibers are still distant. This condition is different from DBM group that has attained the formation of collagen fiber bundles.
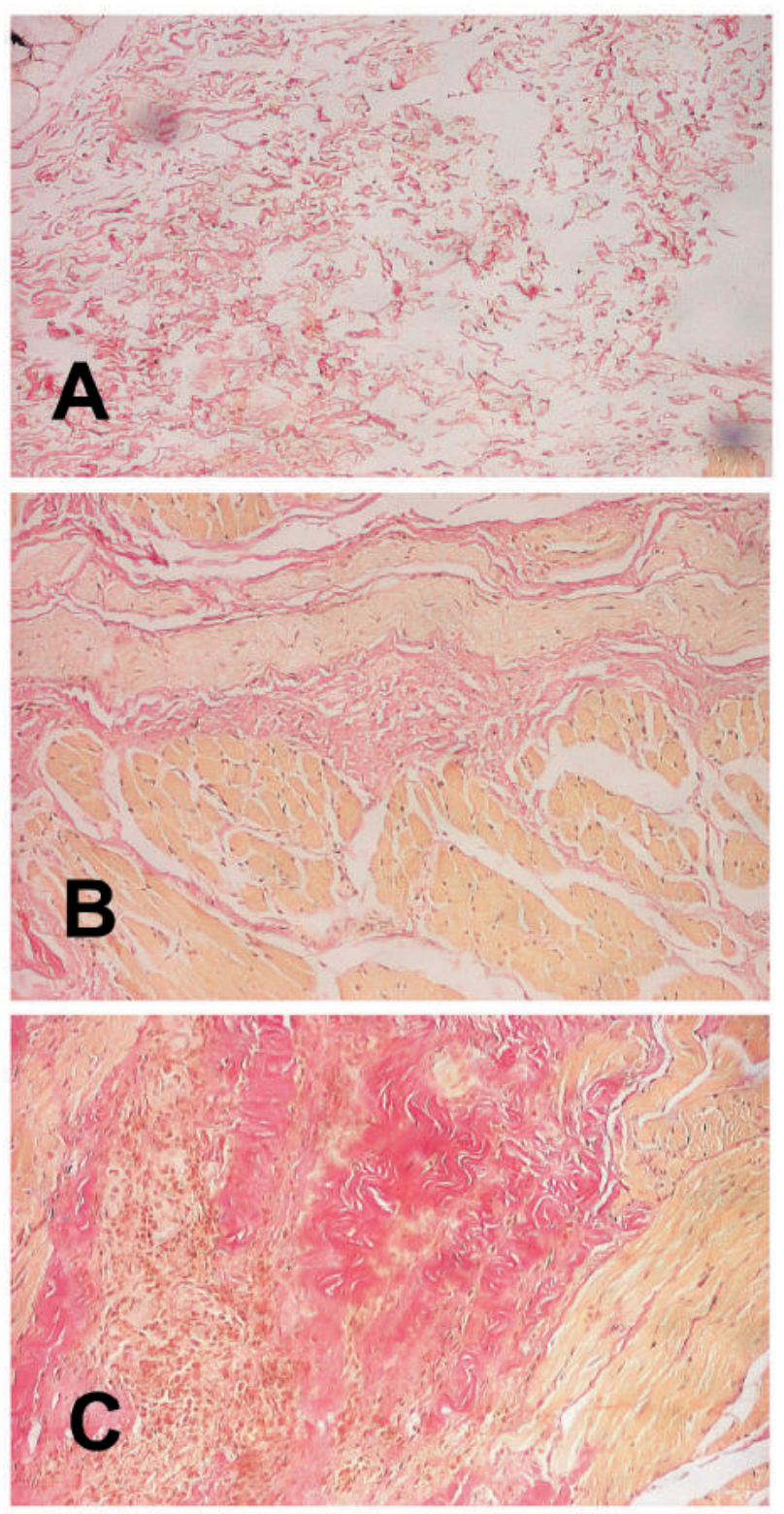

Figure 1. a) Thin collagen density (grade 1); b) Medium collagen density (grade 2); c) Thick collagen density (grade 3). 
The collagen fiber bundles increase in number and density on day 5 after the prevalence of wound. The control group shows a density classified as less than medium category (Figure 3), observed at 400x zoom. This circumstance is indicated by the closer distance among fibers. The existence of collagen fiber bundles begins to appear on days 7 and 10 . This differs from the DBM group that has been dense on day 7 and keeps increasing so as to look extremely dense on day 14.

Table 1. Means and standard deviations of the density of gingival collagen fiber for control group and DBM based on observation days $(n=30)$

\begin{tabular}{ccc}
\hline \multicolumn{3}{c}{ Mean \pm SD } \\
\hline Day & Control & DBM \\
\hline 1 & $1,20 \pm 0,40$ & $1,13 \pm 0,34$ \\
3 & $1,56 \pm 0,56$ & $2,06 \pm 0,58$ \\
5 & $1,83 \pm 0,69$ & $2,56 \pm 0,50$ \\
7 & $2,16 \pm 0,69$ & $2,66 \pm 0,47$ \\
10 & $2,20 \pm 0,61$ & $2,86 \pm 0,34$ \\
14 & $2,43 \pm 0,50$ & $3,00 \pm 0,00$ \\
\hline
\end{tabular}

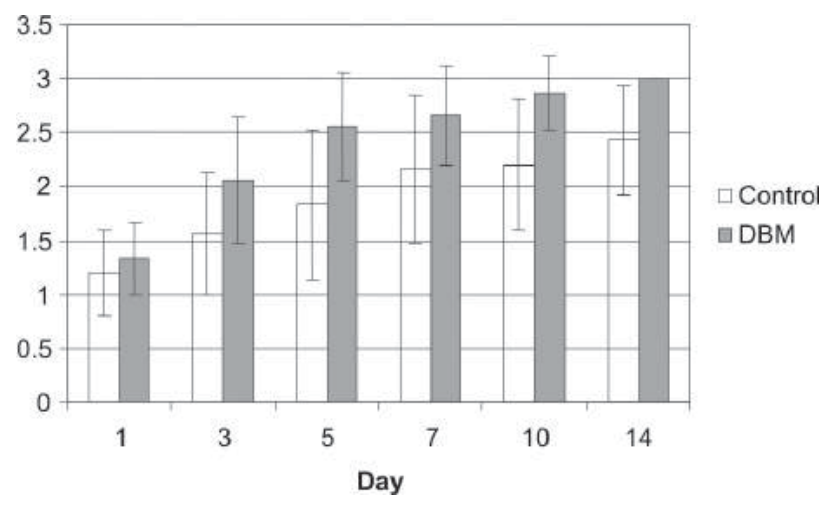

Figure 2. The increasing pattern of the density of gingival collagen fiber based on observation days for control group and DBM.

In general, clinical description on day 1 postextraction shows inflammation alongside white layer of thin fibrin surrounding the area of wound in gingival. Three days after surgery, the DBM group shows the appearance of granulation tissues that look like pink tissues, and they can be distinguished from surrounding tissues. The wound is still concave and has yet to be closed perfectly by granulation tissues, except for the sewn area. Meanwhile, the wound edge is still partly white. This condition has not looked apparently different from that of control group whose necrotic tissues are still dominant.
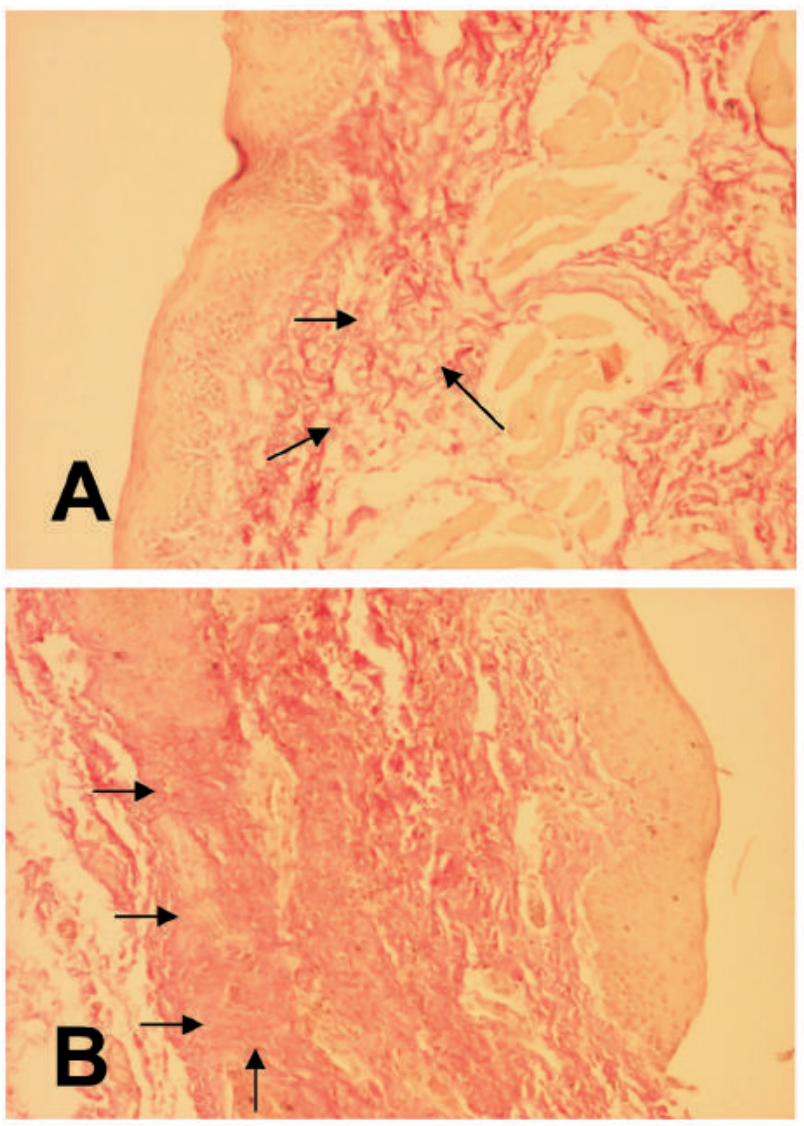

Figure 3. The density of collagen fiber as shown by the arrows for control group (A) and DBM group (B) on day 5 after the prevalence of extraction wound. In Figure B, it appears that collagen bundles have formed numerously (400x zoom).

Five days post-surgery, the DBM group shows the prevalence of granulation tissues that appear to be pink tissues and are easily distinguished from surrounding tissues. Wound trace is still slightly concave and has yet to be perfectly closed by the granulation tissues. Some specimens are found with no fibrin tissues. For the control group, granulation 
tissues have formed although wound still appears to be very concave. On day 7 post-surgery, rabbits augmented by DBM show that granulation tissues have closed perfectly. Fibrin is not seen any longer, and layer color has been difficult to differentiate from surrounding tissues. For the control group, wound still appears to be concave and has yet to close perfectly.

On day 10 post-extraction, the control group shows that wound has closed, and part of the tissue color has been difficult to differentiate from surrounding tissues. For the group augmented by DBM, it is observed that gingival has united with respect to color with surrounding tissues and gingivals. This is getting very obvious on day 14 when the process is completed such that no distinction can be seen in the edge of the wound. For the control group, although the wound has closed, it has not reached a perfect unity with surrounding gingivals. Subsequently, statistical analysis of the density of gingival collagen fiber is shown in Table 2 below.

Table 2. Significance of the density of gingival collagen fiber for control group and DBM group based on observation days $(n=30)$.

\begin{tabular}{cc}
\hline Day & Significance \\
\hline 1 & 0,492 \\
3 & $0,002^{* *}$ \\
5 & $0,000^{* *}$ \\
7 & $0,004^{* *}$ \\
10 & $0,000^{* *}$ \\
14 & $0,000^{* *}$ \\
\hline
\end{tabular}

Result shows in Table 2 indicates that there is a significant difference in the density of gingival collagen fiber between the two groups on every observation day, except on one day post-extraction as this involves previous collagen that has formed. The finding also implies that DBM is capable of inducing collagen biosynthesis in gingival. Hence, this differs from the case of bone collagen fiber, which is only significantly different on days 10 to 14 after tooth extraction.

\section{Discussion}

A series of events such as chemotaxis, cell division, neurovascularization, the synthesis of new ECM components, as well as the formation and remodeling of scraped tissues are phases involved in the wound healing process. In the process of reepithelization, stroma cell migration, neoangiogenesis, and tissue remodeling, ECM proteolytic degradation is needed. The existence and development of inflammation in the DBMaugmented group in this research appears to be quicker, indicating a good response to the next phases in the wound healing process. It is apparent that growth factors contained in the DBM have functioned perfectly through synergic cooperations with recipient cells. Cell proliferation mechanism involved in the wound healing has occurred through transduction signals. The signals conveyed by growth factors are received by target cell cores such that the primary messengers are then tied with the growth factors. Albert et al. ${ }^{15}$ and Cotran et al. ${ }^{24}$ report that the tie, which occurs through phosphorilation process, will activate receptors that in turn will trigger second messenger mechanism in cytoplasm with kinase protein. The prevalence of this mechanism causes extracellular signals to change into intracellular signals that can enter into cell cores. These signals are attached to certain parts in DNA that subsequently lead to transcription process, and further translation process then yields protein. Accordingly, cells will embark on the cyclical stage of cells to proliferate.

Proliferation phase in the healing process is very important, and signs corresponding with this phase include the prevalence of: re-epithelization, angiogenesis, and granulation tissues. Clinical observation results show that the formation of granulation tissues has begun three days after the extraction wound in the DBM group. The granulation tissues are composed of scaffolds filled with fibronectin, fibroblast, blood capillaries, and increasing amount of collagen type I and type III. During the formation of granulation tissues, fibroblast is stimulated by TGF- $\beta$ for creating new ECM protein. Myofibroblast apoptosis and vascular cells intermediate the transition of granulation 
tissues to become scraped tissues. The final result of this is a remodeling, which is synthesized collagen ${ }^{25}$.

Retepeg begins appearing on day 5 in the healing process and continuously forms although it is still short and wide. The formation of retepeg indicates the beginning of maturity of epithelial cells. This circumstance has yet to be found in the control group. As the times passes, the DBM group shows barely distinguished tissue color from surrounding tissues after seven days. Meanwhile, the control group on day 7 shows wound that has closed but is still slightly concave, and it is found that one specimen has begun forming retepeg. After 10 days post-extraction, the DBM group in the healing process appears to have a more compact and longer retepeg reminiscent to a finger. This circumstance is attained by the control group on day 14 for only one specimen. Clinical figures show that the wound closure by granulation tissues is supported by microscopic pictures of retepeg, which is formed quicker in the DBM group. This indicates the ability of DBM to induce collagen biosynthesis and reepithelization.

In general, wound healing process in mouth mucosa nearly resembles wound repair in coetaneous ${ }^{26}$. The difference lies in the gingival wound where keratinocyte migrates directly to fibrinfibronectin matrix without contacting with collagen ${ }^{26,27}$. The wound healing in mouth mucosa is relatively faster, and scraped tissues are seldom forming in this case. In reality, the wound healing of mouth mucosa is reminiscent to the wound healing of fetal. Fibroblast in adult gingival is located in string tissue papilla, and some of its components share with the fibroblast of fetal. There are several factors in saliva, such as growth factor and ion (magnesium and calcium), that function to decrease some material components that may influence the gingival healing ${ }^{27}$. The moisturization of mouth by saliva also functions to help heal wound.

Normal gingival commonly comprises collagen types I and III, but $99 \%$ of them embrace collagen type IV that is intertwined with lamina basal whereas $01 \%$ of them are produced by epithel. In this research, it is shown that the surge of the density of collagen fiber occurs on days 5 and 7 in the DBM group. This finding is supported by Fonesca and Walker ${ }^{28}$, who report that the formation of collagen fiber reaches its peak between those days. Statistical analysis on the DBM group significantly shows collagen formed is much denser for all sample based on observation days, indicating a good organization in ECM. As known, ECM physically provides an environment where cells live, and it functions as the scaffold of tissues and facilitates cell migration during wound recovery. The balance between synthesis and ECM's tight division is required by all tissues to function normally. The amount of composition of ECM is controlled by growth factors and mechanical pressure activities in tissues ${ }^{29,30}$. Accordingly, it shows that DBM powder allograft as an augmentation material has an ability to hasten gingival reconstruction by inducing biosynthesis stimulation of collagen fiber and re-epithelization.

One of the parameters of gingival healing is the growth of collagen fiber. The effect of gingival's soft tissue healing augmented with DBM powder allograft is likely caused by the prevalence of various contained growth factors, such as PDGF and TGF- $\beta$, which synergically cooperate with recipient cells so as to influence the proliferation of cells involved in the gingival healing. PGDF mechanism as reported by Graves and Chonchran ${ }^{31}$ has shown the characteristic of pleitropic effects on all wound repairs in the processes of tissue repairs and regeneration. PDGF is one of the factors that stimulates soft tissue healing ${ }^{32}$. It also functions as potential mitogen for string tissues' cells and to stimulate fibroblast chemotaxis, neutrophil, and macrophage ${ }^{33}$. PDGF has an ability to activate microphage and to produce and secrete other growth factors that are crucial to various aspects in the healing process. PDGF stimulates fibronectin production ${ }^{34}$ and hyaluronic acid ${ }^{35}$. Expressions of various GDFs after the laceration in soft tissues enable the occurrence of regulation and regeneration processes in tissue repairs.

Previous research has provided much evidence that acidic and basic fibroblast growth factors stimulate DNA synthesis and cell replication ${ }^{36}$ and 
that bFGF hastens epithelization process ${ }^{37}$. TGF- $\beta$ has proved to be a strong promoting factor in the formation of ECM in several cell types. In the repairing process, TGF- $\beta$ is cytokine that eliminates the recruitment of inflammatory cells ${ }^{38}$. However, TGF- $\beta$ can also function as chemotactic and mitogenic for neutrophil, lymphocyte, monocyte, macrophage, and fibroblast ${ }^{39}$. The role that TGF- $\beta$ plays during the proliferation process is its ability to stimulate angiogenesis and collagen deposition in tissues ${ }^{39,}{ }^{40}$. In the maturation phase of healing process, TGF- $\beta$ plays a role in controlling excessive ECM components by conducting obstructing mechanisms on all substances that possibly divide or degrade them. In addition, it also plays a role in apoptosis process that prevails during wound maturation $^{41}$

\section{Conclusion}

Findings of this research conclude that DBM augmentation in the alveolus bone of rabbit's mandible after the extraction of incisivus tooth has significantly increased the density of gingival collagen fiber from three days on after the augmentation. Hence, DBM allograft is capable of hastening the wound healing process.

\section{Acknowledgement}

I am very grateful to Prof. dr. Abdul Salam M. Sofro, Ph.D., Prof. Dr. drg. A. Supartinah Santoso, S.U., Sp.K.G.A., Prof. dr. Marsetyawan, M.Sc., Ph.D., and Prof. drh. Widya Asmara, Ph.D. for their valuableOdiscussions. My token of appreciation is addressed to Dr. Totok Utoro, Ph.D. for our discussion on the determination of the density of collagen fiber. Eventually, I thank Dr. Didik Setyo, Dr. Rini Maya Puspita, and Dr. Andreas AK Tandelilin for their assistance to be blind reviewers in this research.

\section{Reference}

1. Mercier P. 1997. Resorption patterns of the residual ridge. In Block MS, Kent JN, editors Endosseus Implants for Maxillofacial Reconstruction. W.B. Saunders Co Phil., 10-16.
2. Zoldos J, Kent JN. 1995. Healing of Endosseous Implants for Maxillofacial Reconstruction. WB Saunders Co. Phil.

3. Delloye, $\mathrm{CH}, 1999$. The use of freeze-dried mineralized and demineralized bone. In Phillips GO, Strong DM, R von Versen. Nather A, editors Advances in Tissue Banking. World Scientific Publishing Co. Pte Ltd Printed Singapore, UtoPrint, Vol 3.

4. Marx RE, Snyder RM, Kline SN. 1979. Cellular survival of human marrow during replacement of marrow-cancellous bone grafts. J Oral Surgery, 37.

5. William H Petri III, 1993. Theree M, Wilson. Clinical evaluation of antibiotic supplemented bone allograft. J Oral Maxillofacial Surgeon, 51: 982-5.

6. Reddi AH, Wientroub, Muthukumaran N. 1987. Biologic principles of bone induction. Orthopedic of North America, 18: 207-12.

7. Wang EA. 1993. Bone morphogenetic proteins (BMPs): Therapeutic potential in healing bone defects. Trends in Biotechnology, 11: 379-83.

8. Tandelilin RTC, Sofro ASM, Santosa AS, Soesatyo MHNE, Asmara W. 2006. The density of collagen fiber in alveolus bone of rabbit after augmentation with powder demineralized bone matrix post incisivus extraction. Dent. J, 39 (2): 43-7.

9. Tandelilin RTC. 2006. The effectivenes of Demineralized Bone Matrix augmentation on rabbit mandibular osteoblast density after incisor extraction. Indonesian J Dent. Special ed, 13: 297302.

10. Wozney JM. 2002. Overview of bone morphogenetic proteins. Spine., 27 (165): 52-8.

11. Brunsvold A, Mellonig JT. 2000. Bone graft and periodontal regeneration. J Periodontology I:8091.

12. Rubin E, Farber JL. 1995. Essential Pathology, $2^{\text {nd }}$ ed. JB Lippincot Co. Philapdelphia.

13. Peterson LJ, Ellis III, Hupp JR, Tucker MR. 1997. Cotemporary Oral and Maxillofacial Surgery, $3^{\text {rd }}$ ed. Mosby, St Louis.

14. Bennett NT, Schultz GS. 1993. Growth factors and wound healing: Biochemichal properties of growth factors their receptors. Am J Sur, 165: 728-37.

15. Cotran R, Kumar V, Collins T., 1999. Tissue Repair: Cellular Growth, Fibrosis, and wound healing. In Robbins Pathologic Basic of Disease. $8^{\text {th }}$ ed, Philadelphia, WB. Sounders Co, 89-112. 
16. Jungueira LC, Carneiro J. 1995. Histologi Dasar. Alih bahasa oleh Tambayong J. Edisi 3. Jakarta: Penerbit Buku Kedokteran EGC, 89-115, 370-81.

17. Prockop DJ, Kiviriko KI. 1995. Collagen: Molecular biology, disease, and potentials for therapy. Annu Rev Biochem, 64: 403-34.

18. Avery JK. 1994. Oral development and Histology. Second edition. Thieme Med Pub, Inc. New York.

19. Fawcett DW. 1994. A Textbook of Hystology, $12^{\text {th }}$ ed. Chapman \& Hall, New York, 71-90.

20. Cate T. 1994. Oral Histology, Development Structure and Function, $3^{\text {rd }}$ ed. The CV Mosby Co. St Louis-Baltimore, Toronto, 89-245.

21. Phillips C, Wenstrup RJ. Biosynthetic and Genetic Disorders of Collagen. 1992. In Cohen IK, Dielgeman RF, Lindblad WJ, eds. Wound Healing - Biochemichal and Clinical Aspects: WB. Saunders Company.

22. Sodek J. 1977. A Comparison of the rates of synthesis and turnover of collagen and noncollagen protein in adult rat periodontal tissues and skin using a microassay. Arch Oral Biol, 22: 655-65.

23. Marzoeki D. 1993. Ilmu Bedah-Luka dan Perawatannya. University Press- Surabaya, 4

24. Alberts B, Bray D, Lewis J, Raff M, Roberts K, Watson JD. 2000. Molecular Biology of The Cell, $3^{\text {rd }}$ ed. Garland Publishing, New York, 403.

25. Yamaguchi Y, Yoshikawa K. 2001. Coetaneous wound healing: an update. J Dermatol, 28: 52134.

26. Lajarva H, Salo T, Haapasaimi K, Kramer RH, Heino J. 1993. Expression of integrins and basement membrane components by wound keratinocytes. J Clin Invest, 92: 1425-35.

27. Hakkinen, L, Uitto, VJ, Larjava, H. 2000. Cell biology of gingival wound healing. Periodontology 2000, 24:127-52.

28. Fonseca RJ, Walker RV. 1991. Oral and Maxillofacial Trauma. WB Saunders Co. Philadelphia, 1: 13-31.

29. Eckes B, Zigrino P, Kessler D. 2000. Fibroblastmatrix interactions in wound healing and fibrosis. Matrix Biol, 19: 325.

30. Geiger B, Bershadsky A, Pankov R, Yamada KM. 2001. Transmembrane crosstalk between the extracellular matrix-cytoskeleton crosstalk. Nat Rev Cell Biol, 2: 793.
31. Graves DT, Concran DL. 1990. Mesenchymal cell growth factors. Crit Rev Oral Biol Med, 1: 17-36.

32. Deuel TF, Kawahara RS, Mustoe TA, Pierce AF. 1991. Growth factors ang wound healing: platelet-derived growth factor as a model cytokine. Ann Rev Med, 42: 567.

33. Heldin CH, Westermark B. 1999. Mechanism of action and in vivo role of platelet-derived growth factor. Physiol Rev, 79: 1283.

34. Blatti SP, Foster DN, Ranganatan G, Moses HL, Getz MJ. 1998. Induction of fibronectin gene transcription and mRNA is a primary response to growth factor stimulation of AKR-2B cells. Proc Natl Acad Sci USA, 85: 919.

35. Bauer EA, Cooper TW, Huang JS, Altman J, Deuel TF. 1993. Stimulation of in vitro human skin collagenase expression by platelet- derived growth factor B chain during wound repair in humans. J Clin Invest, 91: 2065.

36. Canalis E, Mc Carty T, Centrella M. 1988. Effects of basic fibroblast growth factor on bone formation in vitro. J. Clin Invest, 81: 1572-7.

37. Woo HM, Kim MS, Kweon OK, Kim DY, Nam TC, Kim JH. Effects of amniotic membrane on epithelial wound healing and stromal remodelling after excimer keractectomy in rabbit cornea. Br. J. Opthalmol. 2001, 85: 345-9.

38. Reibman J, Meixler S, Lee TC. 1991. Transforming Growth Factor beta 1, a potent chemo-attractant for human neutrophils, by passes classic signaltransduction pathways. Proc Natl Acad Sci US, 88: 6805.

39. Roberts AB, Spron MB, Assoian RK, Smith J, Roche NS, Wakefield LM, Heine UI, Liotta LA, Kehrl JH, Faucci AS. 1986. Transforming Growth Factorbeta: rapid induction of fibrosis and angiogenesis in vivo and stimulation of collagen formation in vitro. Proc Natl Acad Sci US., 83 :4167-71.

40. Beck LS, Deguzman. 1991. Lee Wp, Xu Y, Mc Fatridge LA, Amento EP. TGF-beta 1 accelerates wound healing: reversal of steroid-impaired healing in rats and rabbits. Growth Factors, 5: 295.

41. Yanagihara K, Tsamraya M. 1992. Transforming growth factor beta 1 induces apoptotic cell death in cultured human gastric carcinoma cells. Cancer Res, 52: 40-2. 